\title{
Elevated serum growth differentiation factor 15 levels are associated with thyroid nodules in type 2 diabetes aged over 60 years
}

\author{
Hongmei Zhang ${ }^{1}$, Weiwei Zhang ${ }^{1}$, Xiaofang Tu${ }^{1}$, Yixin Niu ${ }^{1}$, Xiaoyong Li ${ }^{1}$, Li Qin ${ }^{1}$, \\ Zhen Yang ${ }^{1}$ and Qing Su ${ }^{1}$ \\ ${ }^{1}$ Department of Endocrinology, Xinhua Hospital Affiliated to Shanghai Jiaotong University School of Medicine, Shanghai \\ 200092, China \\ Correspondence to: Qing Su, email: suqingxinhua@163.com \\ Zhen Yang, email: zhenyang1020@hotmail.com \\ Keywords: thyroid nodule, growth differentiation factor 15, type 2 diabetes \\ Received: February 15, $2017 \quad$ Accepted: March 30, $2017 \quad$ Published: April 21, 2017 \\ Copyright: Zhang et al. This is an open-access article distributed under the terms of the Creative Commons Attribution License 3.0 (CC \\ BY 3.0), which permits unrestricted use, distribution, and reproduction in any medium, provided the original author and source are \\ credited.
}

\section{ABSTRACT}

In order to investigate whether serum growth differentiation factor 15 is associated with thyroid nodules in type 2 diabetes. We recruited 723 type 2 diabetic patients aged over $\mathbf{3 0}$ years who attended the clinic of Endocrinology of Xinhua Hospital from January 2013 to January 2015. Thyroid nodule was diagnosed by thyroid ultrasonographic examination. Serum growth differentiation factor 15, thyroid function, thyroid autoantibodies, thyroglobulin and other biochemical indicators were measured and compared between thyroid nodule positive and negative groups. We found that overall, serum growth differentiation factor 15 levels were significantly higher in subjects with thyroid nodules compared with nodule negative subjects $(181.76 \pm 98.49 \mathrm{pg} / \mathrm{ml} \mathrm{vs}$. $162.32 \pm 83.63 \mathrm{pg} / \mathrm{ml}, \mathrm{p}<0.05)$, and this was influenced by age. In the patients over 60 years, this difference became more significant $(211.23 \pm 103.66 \mathrm{pg} / \mathrm{ml} \mathrm{vs} .177 .38 \pm 85.51$ $\mathrm{pg} / \mathrm{ml}, \mathrm{p}<0.01)$, but in patients under 60 years, there was no difference between the two groups. Multivariate logistic regression analysis showed that serum growth differentiation factor 15 levels were independently associated with thyroid nodule in diabetic patients over 60 years $(P<0.001)$. After multiple adjustments, the odds ratios were substantially higher for thyroid nodule (odds ratio $2.63,95 \%$ confidence interval 1.30-5.13, $\mathrm{p}<0.01$ ) in the highest growth differentiation factor 15 quartile compared to those in the lowest quartile in patients over 60 years. In conclusion, serum growth differentiation factor 15 is increased significantly in subjects with thyroid nodules in type 2 diabetic patients aged over 60 years.

\section{INTRODUCTION}

Growth differentiation factor $15(\mathrm{GDF}-15)$ is structurally similar to the human transforming growth factor $\beta$ (TGF- $\beta$ ), also being called nonsteroidal anti-inflammatory drug (NSAID)-activated gene-1 (NAG-1), macrophage inhibitory cytokine 1 (MIC-1), prostate differentiation factor (PDF), placental bone morphogenetic protein (PLAB), and placental TGF- $\beta$ (PTGF- $\beta$ ) [1]. In the normal physiological states, the expression level of GDF-15 is very low in the majority cell types and tissues except for the macrophages and placenta [2]. In conditions of acute injury, inflammation, and cancer, GDF-15 will be expressed at a dramatically high level [3-5]. GDF-15 is overexpressed in numerous types of tumors such as colon cancer, prostate cancer, pancreatic cancer, breast cancer, and thyroid carcinomas [6, 7]. Measuring GDF-15 levels can be used in the diagnosis and management of the diseases. Elevated expression levels inside the primary tumor are related to increased serum levels of GDF-15, suggesting a constant release of GDF-15 from the primary tumor into the blood flow [8]. Actually, serum GDF-15 levels are often increased in patients suffering from different types of cancer, including ovarian cancer, pancreatic 
cancer, and prostate cancer. Therefore, GDF-15 seems to be involved in regulating tumor cell growth.

Thyroid nodule is one of the common benign thyroid disorders [9]. With the widely used technology of modern ultrasound the prevalence of thyroid nodules has risen up to $76 \%$ [10], but the molecular mechanisms of thyroid nodules are still not clear. The natural occurring thyroid growth heterogeneity could provide a reasonable explanation for the early stages of nodule formation. If there is a high inherent growth potential in a thyrocyte or if the thyrocyte is affected by some protooncogene overexpression or some growth factor or it is hit by some oncogene or other molecular events, the cell will proliferate to form a tumor [11].

Diabetes mellitus (DM) and thyroid disease are the two most common diseases in the endocrine system [12]. Currently, a meta-analysis of 10920 diabetic patients has shown that the frequency of thyroid disease was $11 \%$ [13]. Some researchers have found that patients with type 2 DM had increased thyroid volumes and elevated prevalence of thyroid nodule [14], but research about the connection between type $2 \mathrm{DM}$ and thyroid nodule are still sparse. Some studies revealed that circulating levels of GDF-15 in patients with recognized type 2 diabetes were much higher $[15,16]$, and GDF-15 is related to increased cancer risk in type 2 diabetes [17]. Since GDF-15 has potential cell growth promoting activity and its circulating concentrations in type 2 diabetes are elevated, it is logical to regard GDF-15 as a promising candidate for risk assessment for thyroid nodule in type 2 diabetic patients. To better evaluate the possible role of GDF-15 in thyroid nodule development in type 2 diabetes, we examined the relationship between serum GDF-15 levels and thyroid nodule in type 2 diabetic patients.

\section{RESULTS}

\section{Baseline characteristics}

Of the 723 studied participants, 402 subjects were thyroid nodule positive (226 male). As shown in Figure 1, the serum GDF-15 levels were significantly higher in subjects with thyroid nodules compared with nodule negative subjects $(181.76 \pm 98.49 \mathrm{pg} / \mathrm{ml}$ vs. $162.32 \pm 83.63$ $\mathrm{pg} / \mathrm{ml}, \mathrm{p}<0.05)$. After being divided by age, this difference became more significant $(211.23 \pm 103.66 \mathrm{pg} / \mathrm{ml}$ vs. $177.38 \pm 85.51 \mathrm{pg} / \mathrm{ml}, \mathrm{p}<0.01)$, but in patients under 60 years, there was no difference between the two groups. The clinical characteristics of participants were shown in Table 1 . When compared with thyroid nodule negative subjects, the thyroid nodule positive ones had significantly older age $(p<0.001)$, lower FT3 and FT4 levels $(p<0.05)$, and increased thyroid volumes $(\mathrm{p}<0.05)$.

Correlation analysis showed a remarkable correlation between GDF-15 and age $(\mathrm{r}=0.351, \mathrm{p}<0.001)$; GDF-15 and $\log _{10} \mathrm{Tg}(\mathrm{r}=0.138, \mathrm{p}<0.01)$; GDF-15 and CHO ( $\mathrm{r}=-0.158, \mathrm{p}<0.001)$; GDF-15 and LDL $(\mathrm{r}=-0.161$, $\mathrm{p}<0.001$ ) (see Table 2 ). A multiple stepwise regression analysis was used to evaluate the independent variables that may have an effect on GDF-15 serum levels. The main determinants of GDF-15 are age $(\beta=0.375, \mathrm{p}<0.001)$; $\operatorname{Tg}(\beta=0.155, \mathrm{p}<0.01)($ see Table 3$)$.

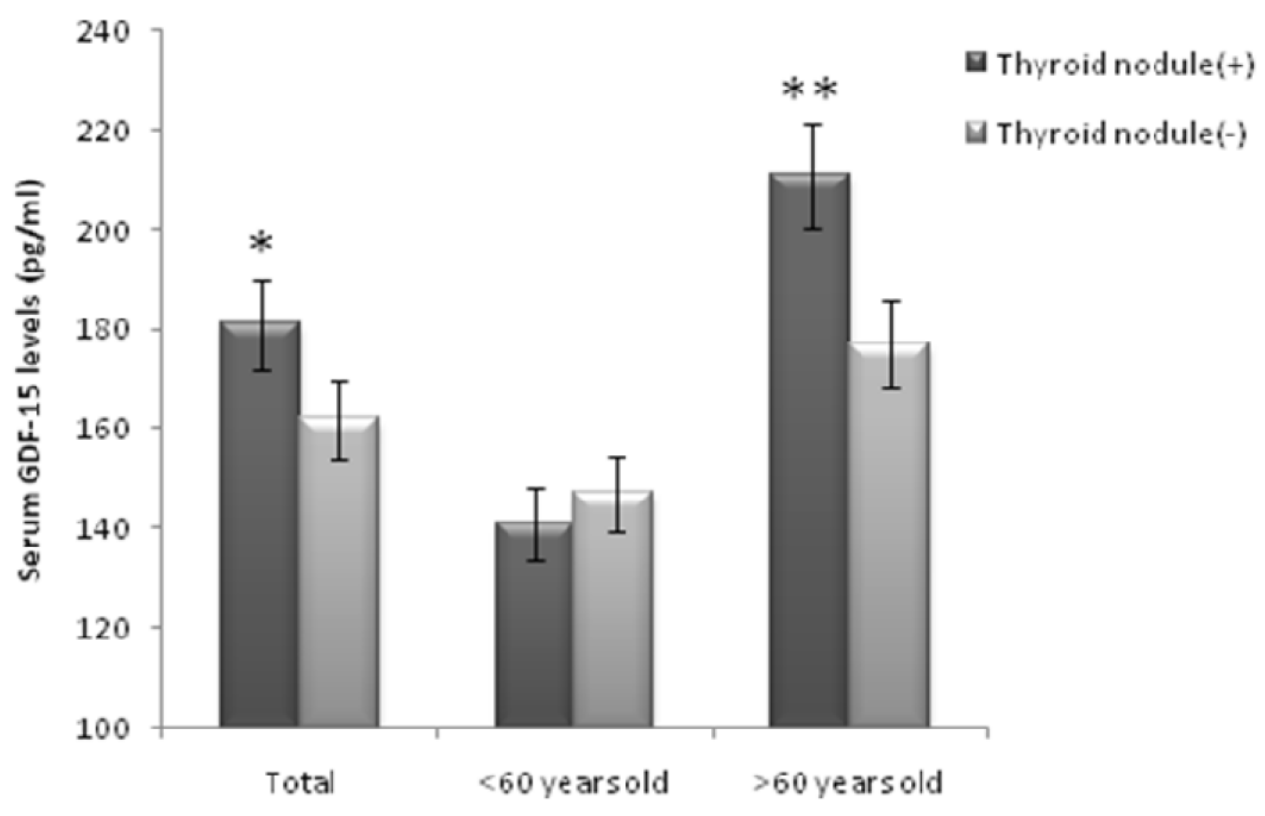

Figure 1: Serum GDF-15 levels in thyroid nodule positive and thyroid nodule negative groups. Data are shown as means \pm SD. ${ }^{*} \mathrm{p}<0.05, * * \mathrm{p}<0.01$. 
Table 1: Clinical and laboratory characteristics of study subjects

\begin{tabular}{|c|c|c|c|}
\hline Characteristics & Thyroid nodule $(+)$ & Thyroid nodule (-) & P value \\
\hline $\mathrm{N}$ & 402 & 321 & \\
\hline Age (year) & $63.59 \pm 11.78$ & $58.08 \pm 13.69$ & $<0.001$ \\
\hline Sex (Male/Female) & $226 / 176$ & $206 / 115$ & 0.053 \\
\hline BMI $\left(\mathrm{kg} / \mathrm{m}^{2}\right)$ & $24.84 \pm 3.86$ & $25.03 \pm 3.99$ & 0.538 \\
\hline SBP (mm Hg) & $133.01 \pm 15.85$ & $131.78 \pm 15.54$ & 0.317 \\
\hline DBP (mm Hg) & $76.93 \pm 9.72$ & $77.79 \pm 10.15$ & 0.264 \\
\hline TT3 (nmol/1) & $1.45 \pm 0.40$ & $1.99 \pm 0.77$ & 0.436 \\
\hline TT4 (nmol/1) & $115.21 \pm 21.07$ & $117.98 \pm 28.26$ & 0.174 \\
\hline FT3 (pmol/l) & $4.41 \pm 0.74$ & $4.58 \pm 1.11$ & $<0.05$ \\
\hline FT4 (pmol/l) & $17.49 \pm 3.52$ & $18.39 \pm 5.12$ & $<0.05$ \\
\hline TSH (uIU/ml) & $1.75(0.94-2.57)$ & $1.82(0.77-2.71)$ & 0.371 \\
\hline TPOAb (IU/ml) & $35.90(28.00-47.60)$ & $36.60(28.78-61.53)$ & 0.223 \\
\hline TRAb (IU/ml) & $0.30(0.30-0.61)$ & $0.32(0.30-1.09)$ & 0.870 \\
\hline TGAb (U/ml) & $18.95(14.60-32.40)$ & $21.90(17.23-47.7)$ & 0.535 \\
\hline $\operatorname{Tg}(\mathrm{ng} / \mathrm{ml})$ & $8.24(4.17-13.28)$ & $7.08(4.35-20.73)$ & 0.088 \\
\hline Thyroid Volume (ml) & $8.39 \pm 4.32$ & $7.42 \pm 3.25$ & $<0.05$ \\
\hline Insilin (pmol/1) & $98.35 \pm 18.36$ & $81.48 \pm 15.24$ & 0.133 \\
\hline $\mathrm{TG}(\mathrm{mmol} / \mathrm{l})$ & $1.94 \pm 0.31$ & $2.34 \pm 0.56$ & 0.150 \\
\hline $\mathrm{CHO}(\mathrm{mmol} / \mathrm{l})$ & $4.74 \pm 1.16$ & $4.72 \pm 1.06$ & 0.806 \\
\hline $\mathrm{LDL}(\mathrm{mmol} / \mathrm{l})$ & $2.85 \pm 0.79$ & $2.83 \pm 0.76$ & 0.790 \\
\hline $\operatorname{HDL}(\mathrm{mmol} / \mathrm{l})$ & $1.36 \pm 0.48$ & $1.60 \pm 0.44$ & 0.436 \\
\hline HbA1C (\%) & $9.68 \pm 2.33$ & $10.10 \pm 3.58$ & 0.219 \\
\hline FBS $(\mathrm{mmol} / \mathrm{l})$ & $8.75 \pm 3.33$ & $8.40 \pm 3.02$ & 0.267 \\
\hline
\end{tabular}

Data are means $\pm \mathrm{SD}$, median (interquartile range) or number (percent).

\section{Association between GDF-15 and thyroid nodule}

Since GDF-15 is correlated with age, and multiple logistic regression analysis indicated that age was independently associated with thyroid nodule $(\mathrm{P}<0.001)$ (Table 4). We further divided the subjects into two groups according to age at 60 years old, and we found that GDF15 was independently associated with thyroid nodule in patients over 60 years $(\mathrm{P}<0.01)$ (Table 4$)$. In patients under 60 years old, GDF-15 was not related to thyroid nodule.

Table 5 displays the ORs for thyroid nodule according to GDF-15 quartiles ( $\leq 106.24 ; 106.25-149.79$; $149.80-214.08$; and $\geq 214.09 \mathrm{pg} / \mathrm{ml}$, respectively). As assumed, we found increased ORs for thyroid nodule from the 1st to the 4th GDF-15 quartiles ( $\mathrm{P}<0.01$ for trend). In the highest GDF-15 quartile, the adjusted ORs for thyroid nodule was 2.63 (95\% CI, 1.30 to 5.13) after adjusting for gender, FT3, FT4, and thyroid volume.

\section{DISCUSSION}

The major new finding of the present study is that serum GDF-15 level is positively associated with thyroid nodule in type 2 diabetic patients aged over 60 years. These results are consistent with the hypothesis that serum GDF-15 is a determinant of thyroid nodule in type 2 diabetic patients aged over 60 years. Our findings suggest that serum GDF-15 may be involved in the higher thyroid nodule risk observed in elderly type 2 diabetic subjects.

GDF-15, also known as macrophage inhibitory cytokine 1 , was described as a distinct member of TGF- $\beta$ superfamily [1]. GDF-15 expression and secretion are both increased in some malignant tissues and cancer cell lines when compared with their normal tissues or cells $[18,19]$. In addition, the serum GDF-15 levels in human cancer patients are high, with declining patient 
Table 2: Crude and partial correlation between serum GDF-15 and clinical parameters in the study subjects

\begin{tabular}{lcc}
\hline Variable & Crude $\mathbf{r}$ & ${\text { Partial } \mathbf{r}^{\dagger}}^{\dagger}$ \\
\hline Age $(\mathrm{year})$ & $0.351^{* *}$ & - \\
$\mathrm{BMI}\left(\mathrm{kg} / \mathrm{m}^{2}\right)$ & 0.014 & 0.046 \\
$\mathrm{SBP}(\mathrm{mmHg})$ & 0.034 & 0.029 \\
$\mathrm{DBP}(\mathrm{mmHg})$ & 0.026 & 0.022 \\
$\mathrm{TT3}(\mathrm{nmol} / \mathrm{l})$ & -0.071 & -0.029 \\
$\mathrm{TT} 4(\mathrm{nmol} / \mathrm{l})$ & 0.042 & -0.083 \\
$\mathrm{FT3}(\mathrm{pmol} / \mathrm{l})$ & $-0.196^{* *}$ & -0.095 \\
$\mathrm{FT} 4(\mathrm{pmol} / \mathrm{l})$ & -0.049 & -0.014 \\
$\log _{10} \mathrm{TSH}(\mathrm{uIU} / \mathrm{ml})$ & 0.037 & 0.024 \\
$\log _{10} \mathrm{TPOAb}(\mathrm{IU} / \mathrm{ml})$ & -0.006 & -0.002 \\
$\log _{10} \mathrm{TRAb}(\mathrm{IU} / \mathrm{ml})$ & -0.069 & -0.048 \\
$\log _{10} \mathrm{TGAb}(\mathrm{U} / \mathrm{ml})$ & 0.009 & -0.033 \\
$\log _{10} \mathrm{Tg}(\mathrm{ng} / \mathrm{ml})$ & $0.177^{* *}$ & $0.138^{*}$ \\
$\mathrm{INS}(\mathrm{pmol} / \mathrm{l})$ & 0.088 & 0.047 \\
Triglycerides $(\mathrm{mmol} / \mathrm{l})$ & 0.024 & 0.082 \\
$\mathrm{CHO}(\mathrm{mmol} / \mathrm{l})$ & $-0.149 *$ & $-0.158^{* *}$ \\
$\mathrm{LDL}(\mathrm{mmol} / \mathrm{l})$ & $-0.123^{*}$ & $-0.161^{* *}$ \\
$\mathrm{HDL}(\mathrm{mmol} / \mathrm{l})$ & -0.028 & -0.020 \\
\hline
\end{tabular}

$* \mathrm{p}<0.01, * * \mathrm{p}<0.001$, †adjusted for age, gender.

Table 3: Multiple stepwise regression analysis showing variables independently associated with the serum level of GDF-15

\begin{tabular}{lccc}
\hline Independent variables & Standardized $\boldsymbol{\beta}$ & $\mathbf{t}$ & P value \\
\hline Age & 0.375 & 7.285 & $<0.001$ \\
$\log _{10} \mathrm{Tg}$ & 0.155 & 3.043 & $<0.01$ \\
\hline
\end{tabular}

The analysis also included gender, FT3, CHO, LDL which were all excluded in the final model.

survival. Measurement of serum GDF-15 level has been proposed as an indicator for cancer progression and risk assessment [20]. The intuitive response is to consider the highly expressed GDF-15 protein as a driving factor in tumor growth. GDF-15 can stimulate the activation of Akt and the extracellular signal-related kinase (ERK) pathway [21]. Except for its direct bioactivity in cancer cells, GDF15 has frequently been reported to modulate the tumoral microenvironment [22] and regulate the immunization. Pro-angiogenesis could be another way for GDF-15 to promote tumor growth. Some research indicated that GDF15 is related to malignant thyroid follicular neoplasia [23], but so far there is no evidence to imply the association between GDF-15 and begin thyroid nodule. Our results supported that GDF-15 may be involved in the formation of thyroid nodules in type 2 diabetes. And thyroglobulin is independently associated with GDF-15. As far as we know, this is the first study to link GDF-15 and thyroid nodule. Large-scale investigations will be needed to testify this connection in the future.

Thyroid nodule is a common disease in clinical practice. The accurate mechanism of thyroid cell proliferation remains unclear. It was reported that impaired glucose metabolism is a risk factor for enlarged thyroid and increased nodule prevalence [14]. Other studies have also revealed that type $2 \mathrm{DM}$ has an effect on the formation of thyroid nodules [24, 25]. Patients with type 2 DM had larger thyroid and elevated risk of thyroid nodule formation [14]. The reason for having higher thyroid nodule prevalence in diabetic patients is uncertain. Some 
Table 4: Multiple logistic regression analysis showing variables independently associated with thyroid nodule

\begin{tabular}{lcccccc}
\hline & Independent variables & B & SE & Wald & $\begin{array}{c}\text { Exp(B) } \\
\text { 95\% CI }\end{array}$ \\
\hline Total & Age & 0.30 & 0.007 & 16.499 & $1.031(1.00-1.05)$ & $<0.001$ \\
$>60$ years & GDF-15 & 0.05 & 0.002 & 7.215 & $1.050(1.01-1.07)$ & $<0.01$ \\
\hline
\end{tabular}

The analysis also included age gender, BMI, FT3, FT4, thyroglobulin, insulin, TG, and thyroid volume which were all excluded in the final model.

Table 5: Adjusted ORs and 95\% CIs for thyroid nodule according to GDF-15 quartiles in subjects

\begin{tabular}{|c|c|c|c|c|c|}
\hline & \multicolumn{4}{|c|}{ ORs $(95 \%$ CI $)$} & \multirow[b]{2}{*}{$P$ value for trend } \\
\hline & $\begin{array}{c}\text { Q1 }(\mathrm{pg} / \mathrm{ml}) \\
\leq 106.24\end{array}$ & $\begin{array}{c}\text { Q2 }(\mathrm{pg} / \mathrm{ml}) \\
106.25-149.79\end{array}$ & $\begin{array}{c}\text { Q3 }(\mathrm{pg} / \mathrm{ml}) \\
149.80-214.08\end{array}$ & $\begin{array}{c}\text { Q4 (pg/ml) } \\
\geq 214.09\end{array}$ & \\
\hline \multicolumn{6}{|l|}{$>60$ years } \\
\hline Model 1 & 1 & $1.39(0.66-2.93)$ & $1.45(0.79-2.64)$ & $\begin{array}{c}2.45 \\
(1.33-5.19)\end{array}$ & $<0.01$ \\
\hline Model 2 & 1 & $1.37(0.63-2.90)$ & $1.41(0.76-2.61)$ & $2.63(1.30-5.13)$ & $<0.01$ \\
\hline \multicolumn{6}{|c|}{$\leqq 60$ years } \\
\hline Model 1 & 1 & $0.9(0.41-2.21)$ & $1.06(0.48-2.35)$ & $1.45(0.70-2.99)$ & $>0.05$ \\
\hline Model 2 & 1 & $0.77(0.32-1.86)$ & $0.85(0.37-1.96)$ & $1.28(0.61-2.69)$ & $>0.05$ \\
\hline
\end{tabular}

Q, Quartile.

Model 1 unadjusted.

Model 2 adjusted for gender, FT3, FT4, and thyroid volume.

studies reported that circulating concentrations GDF15 in patients with type 2 diabetes were much higher $[15,16]$, and GDF-15 is related to cell hyperplasia in type 2 diabetes [17]. It is logical to consider GDF-15 as a risk factor for thyroid cell proliferation in diabetes. Our findings confirmed this, we found serum GDF-15 levels were independently associated with thyroid nodule in diabetic patients over 60 years.

Hypothyroidism is a well-known stimulator of thyroid growth [26]. Another mechanism involved in thyroid cell proliferation is thyroid autoimmunity [27]. The Hashimoto thyroiditis includes proliferating nodules formation, cytological alterations, and nuclear modification similar to papillary thyroid carcinoma [28]. Although we found decreased FT3 and FT4 levels in the subjects with thyroid nodule, but after adjusting age and other confounders, FT3 and FT4 levels were not related to thyroid nodules which means the lower levels of FT3 and FT4 may be caused by old age, which is consistent with previous studies [29]. In the present study, maybe because of the sample size, we didn't find hypothyroidism and thyroid autoimmunity were related to thyroid nodule. And we didn't find GDF15 was associated with hypothyroidism and thyroid autoimmunity either.

Our study has some limitations. Firstly, there was not enough information about the morphological characteristics of thyroid nodules such as nodule diameters and uni-/multinodularity. Secondly, the cytological and/or histopathological outcome of each thyroid nodule has not been assessed. Including these assessments may improve the strength of future studies. Thirdly, because the subjects were from the clinic of our hospital, a single center in China, the study population may not represent the general population.

\section{SUBJECTS AND METHODS}

\section{Subjects}

The participants were from the clinic of Endocrinology of Xinhua Hospital Affiliated to Shanghai Jiaotong University School of Medicine between January 2013 and January 2015. We recruited 723 patients (432 men and 291 women) in total. All of the 723 patients were 
type 2 diabetic and aged over 30 years. Diabetes was diagnosed according to WHO 1999 diagnostic criteria. All participants have a diabetes history of more than 3 years and were under hypoglycemic treatments. Patients with severe cardiovascular disease, renal insufficiency, liver dysfunction were excluded. Informed consent was obtained from all of the participants. The research protocol was approved by the Ethics Committee of Xinhua Hospital Affiliated to Shanghai Jiaotong University School of Medicine.

\section{Thyroid parameters measurements and clinical data collection}

After overnight fasting, peripheral venous blood samples were collected. Thyroid function, thyroid antibodies, thyroglobulin, and insulin were assayed by an automated analyzer (ADVIA Centaur XP, Siemens, Berlin, German). HbA1c was determined by high-performance liquid chromatography (BIO-RAD VARIANT II, California, USA). Blood lipids were measured with an autoanalyzer (Hitachi 7600, Tokyo, Japan). Body mass index (BMI) was calculated as weight in kilograms divided by the square of height in meters. Blood pressure was measured three times from the right arm of patients after 30 min resting in a sitting position; then mean values were calculated.

\section{Measurement of GDF-15}

Serum samples were isolated and stored at $-80^{\circ} \mathrm{C}$ until analysis. The serum GDF-15 levels were detected by ELISA with Duoset kit (DY957; R\&D Systems, Minneapolis, MN) in duplicate according to the recommendations of the manufacturer. The ELISA system possesses an inter-assay coefficient of variation of $4-10 \%$ and intra-assay coefficient of variation of $3-9 \%$, respectively.

\section{Thyroid nodule measurement}

Thyroid ultrasonographic examination was conducted by two experienced ultrasonographists using high-resolution B-mode tomographic ultrasound system (Esaote Biomedica SpA) with $10-\mathrm{MHz}$ transducers. Thyroid nodules are defined as discrete lesions within the thyroid gland that are radiologically different from the surrounding thyroid tissue [30]. Each nodule was measured in three dimensions. The smallest diameter measured is $2-3 \mathrm{~mm}$. We included solid lesions and mixed cystic-solid lesions, but cystic lesions were excluded. Thyroid volume was calculated using the ellipsoid formula: volume $(\mathrm{mL})=$ depth $(\mathrm{cm}) \times$ width $(\mathrm{cm}) \times$ length $(\mathrm{cm}) \times \pi / 6[14]$.

\section{Statistical analysis}

Normally distributed data were shown as means $\pm \mathrm{SD}$, non-normally distributed data were expressed as median (interquartile range) and log-transformed to approximate normality prior to analysis. Unpaired Student's t-test was used to test differences between groups. Correlation coefficients between GDF-15 and other parameters were calculated by Pearson correlation analysis. Multiple stepwise regression analysis was used to determine the relationship between serum GDF-15 and other parameters. Multiple logistic regression models were used to calculate the odds ratios (ORs) for thyroid nodule. Variables entered in the model were chosen according to the clinical and statistical significance. Any variable having a significant univariate test at 0.20 was selected as a candidate for the multivariate analysis. In the end, variables included in the model were age, gender, BMI, FF3, FT4, thyroglobulin, insulin, TG, and thyroid volume. Covariates were removed from the model if they were non-significant and not a confounder. We divided the subjects into two groups by age at 60 years old and analyzed the associations of GDF-15 and thyroid nodule in different age groups. All statistical analysis was conducted using SPSS Statistical Package (version 13.0; SPSS Inc., Chicago, IL). P values $<0.05$ were considered statistically significant.

\section{CONCLUSION}

In conclusion, our study suggests that serum GDF-15 is a marker for the development of thyroid nodule in patients with type 2 diabetes over 60 years old. Measurement of serum GDF-15 could be useful for thyroid nodule risk stratification in the diabetic population.

\section{Abbreviations}

GDF-15 $=$ Growth differentiation factor 15, BMI $=$ body mass Index, $\mathrm{SBP}=$ systolic blood pressure, DBP $=$ diastolic blood pressure, TT3 = total triiodothyronine, TT4 = total thyroxine FT3 = free triiodothyronine, FT4 = free thyroxine, $\mathrm{TSH}=$ thyrotropin, $\mathrm{TPOAb}=$ antithyroid peroxidase antibodies, $\mathrm{TGAb}=$ anti-thyroglobulin antibody, $\mathrm{TRAb}=$ thyrotropin receptor antibodies, $\mathrm{Tg}=$ thyroglobulin.

\section{ACKNOWLEDGMENTS}

This work was supported by grants from National Natural Science Foundation of China (81300642, 81300667, 81370953, 81370935), the Shanghai Science and Technology Commission (10411956600, 14ZR1427400), and Shanghai Health System Outstanding Young Talents Training Program (XYQ2013098). 


\section{CONFLICTS OF INTEREST}

The authors have no conflicts of interest to disclose.

\section{REFERENCES}

1. Bootcov MR, Bauskin AR, Valenzuela SM, Moore AG, Bansal M, He XY, Zhang HP, Donnellan M, Mahler S, Pryor K, Walsh BJ, Nicholson RC, Fairlie WD, et al. MIC1 , a novel macrophage inhibitory cytokine, is a divergent member of the TGF-beta superfamily. Proceedings of the National Academy of Sciences of the United States of America. 1997; 94:11514-11519.

2. Karan D, Holzbeierlein J, Thrasher JB. Macrophage inhibitory cytokine-1: possible bridge molecule of inflammation and prostate cancer. Cancer research. 2009; 69:2-5.

3. Fairlie WD, Moore AG, Bauskin AR, Russell PK, Zhang HP, Breit SN. MIC-1 is a novel TGF-beta superfamily cytokine associated with macrophage activation. Journal of leukocyte biology. 1999; 65:2-5.

4. Welsh JB, Sapinoso LM, Kern SG, Brown DA, Liu T, Bauskin AR, Ward RL, Hawkins NJ, Quinn DI, Russell PJ, Sutherland RL, Breit SN, Moskaluk CA, et al. Large-scale delineation of secreted protein biomarkers overexpressed in cancer tissue and serum. Proceedings of the National Academy of Sciences of the United States of America. 2003; 100:3410-3415.

5. Schober A, Bottner M, Strelau J, Kinscherf R, Bonaterra GA, Barth M, Schilling L, Fairlie WD, Breit SN, Unsicker $\mathrm{K}$. Expression of growth differentiation factor-15/ macrophage inhibitory cytokine-1 (GDF-15/MIC-1) in the perinatal, adult, and injured rat brain. The Journal of comparative neurology. 2001; 439:32-45.

6. Breit SN, Johnen H, Cook AD, Tsai VW, Mohammad MG, Kuffner T, Zhang HP, Marquis CP, Jiang L, Lockwood G, Lee-Ng M, Husaini Y, Wu L, et al. The TGF-beta superfamily cytokine, MIC-1/GDF15: a pleotrophic cytokine with roles in inflammation, cancer and metabolism. Growth Factors. 2011; 29:187-195.

7. Bauskin AR, Brown DA, Kuffner T, Johnen H, Luo XW, Hunter M, Breit SN. Role of macrophage inhibitory cytokine-1 in tumorigenesis and diagnosis of cancer. Cancer research. 2006; 66:4983-4986.

8. Bruzzese F, Hagglof C, Leone A, Sjoberg E, Roca MS, Kiflemariam S, Sjoblom T, Hammarsten P, Egevad L, Bergh A, Ostman A, Budillon A, Augsten M. Local and systemic protumorigenic effects of cancer-associated fibroblastderived GDF15. Cancer research. 2014; 74:3408-3417.

9. Paschou S, Vryonidou A, Goulis DG. Thyroid nodules: alpha guide to assessment, treatment and follow-up. Maturitas. 2017; 96:1-9.

10. Ferraz C, Eszlinger M, Paschke R. Current state and future perspective of molecular diagnosis of fine-needle aspiration biopsy of thyroid nodules. The Journal of clinical endocrinology and metabolism. 2011; 96:2016-2026.

11. Derwahl M. Molecular aspects of the pathogenesis of nodular goiters, thyroid nodules and adenomas. Experimental and clinical endocrinology \& diabetes. 1996; 104:32-35.

12. Hage M, Zantout MS, Azar ST. Thyroid disorders and diabetes mellitus. Journal of thyroid research. 2011; 2011:439463.

13. Kadiyala R, Peter R, Okosieme OE. Thyroid dysfunction in patients with diabetes: clinical implications and screening strategies. International journal of clinical practice. 2010; 64:1130-1139.

14. Anil C, Akkurt A, Ayturk S, Kut A, Gursoy A. Impaired glucose metabolism is a risk factor for increased thyroid volume and nodule prevalence in a mild-to-moderate iodine deficient area. Metabolism. 2013; 62:970-975.

15. Dominguez-Rodriguez A, Abreu-Gonzalez P, Avanzas P. Usefulness of growth differentiation factor-15 levels to predict diabetic cardiomyopathy in asymptomatic patients with type 2 diabetes mellitus. The American journal of cardiology. 2014; 114:890-894.

16. Daniels LB, Clopton P, Laughlin GA, Maisel AS, Barrett-Connor E. Growth-differentiation factor-15 is a robust, independent predictor of 11-year mortality risk in community-dwelling older adults: the Rancho Bernardo Study. Circulation. 2011; 123:2101-2110.

17. Pavo N, Wurm R, Neuhold S, Adlbrecht C, Vila G, Strunk G, Clodi M, Resl M, Brath H, Prager R, Luger A, Pacher R, Hulsmann M. GDF-15 is associated with cancer incidence in patients with type 2 diabetes. Clin Chem. 2016; 62:1612-1620.

18. Welsh JB, Sapinoso LM, Su AI, Kern SG, Wang-Rodriguez J, Moskaluk CA, Frierson HF Jr, Hampton GM. Analysis of gene expression identifies candidate markers and pharmacological targets in prostate cancer. Cancer research. 2001; 61:5974-5978.

19. Park YJ, Lee H, Lee JH. Macrophage inhibitory cytokine-1 transactivates ErbB family receptors via the activation of Src in SK-BR-3 human breast cancer cells. BMB reports. 2010; 43:91-96.

20. Mimeault M, Batra SK. Divergent molecular mechanisms underlying the pleiotropic functions of macrophage inhibitory cytokine-1 in cancer. Journal of cellular physiology. 2010; 224:626-635.

21. Subramaniam S, Strelau J, Unsicker K. Growth differentiation factor-15 prevents low potassium-induced cell death of cerebellar granule neurons by differential regulation of Akt and ERK pathways. The Journal of biological chemistry. 2003; 278:8904-8912.

22. Corre J, Hebraud B, Bourin P. Concise review: growth differentiation factor 15 in pathology: a clinical role? Stem cells translational medicine. $2013 ; 2: 946-952$. 
23. Weber F, Shen L, Aldred MA, Morrison CD, Frilling A, Saji M, Schuppert F, Broelsch CE, Ringel MD, Eng C. Genetic classification of benign and malignant thyroid follicular neoplasia based on a three-gene combination. The Journal of Clinical Endocrinology \& Metabolism. 2005; 90:2512-2521.

24. Rezzonico J, Rezzonico M, Pusiol E, Pitoia F, Niepomniszcze H. Introducing the thyroid gland as another victim of the insulin resistance syndrome. Thyroid. 2008; $18: 461-464$

25. Junik R, Kozinski M, Debska-Kozinska K. Thyroid ultrasound in diabetic patients without overt thyroid disease. Acta Radiologica. 2006; 47:687-691.

26. Kratky J, Vitkova H, Bartakova J, Telicka Z, Antosova M, Limanova Z, Jiskra J. Thyroid nodules: pathophysiological insight on oncogenesis and novel diagnostic techniques. Physiological research. 2014; 63:S263-275.

27. Kim ES, Lim DJ, Baek KH, Lee JM, Kim MK, Kwon HS, Song KH, Kang MI, Cha BY, Lee KW. Thyroglobulin antibody is associated with increased cancer risk in thyroid nodules. Thyroid. 2010; 20:885-891.

28. Cunha LL, Ferreira RC, Marcello MA, Vassallo J, Ward LS. Clinical and pathological implications of concurrent autoimmune thyroid disorders and papillary thyroid cancer. Journal of thyroid research. 2011; 2011:387062.

29. Corsonello A, Montesanto A, Berardelli M, De Rango F, Dato S, Mari V, Mazzei B, Lattanzio F, Passarino G. A cross-section analysis of FT3 age-related changes in a group of old and oldest-old subjects, including centenarians' relatives, shows that a down-regulated thyroid function has a familial component and is related to longevity. Age and Ageing. 2010; 39: 723-727.

30. Cooper DS, Doherty GM, Haugen BR, Kloos RT, Lee SL, Mandel SJ, Mazzaferri EL, McIver B, Pacini F, Schlumberger M, Sherman SI, Steward DL, Tuttle RM. Revised American Thyroid Association management guidelines for patients with thyroid nodules and differentiated thyroid cancer. Thyroid. 2009; 19:1167-1214. 